\title{
THEORETICAL AND SIMULATION PERFORMANCE STUDY OF HYDRAULIC ELECTRIC ENERGY REGENERATIVE SHOCK ABSORBER
}

\author{
Faisal Muhammad Yasin ${ }^{1}$, Xie Fangwei ${ }^{2 *}$, Muhammad Mujtaba ${ }^{3}$, Asad Ali ${ }^{4}$, Muhammad Rizwan Khan ${ }^{5}$ \\ *1,2,3,4,5 School of Mechanical Engineering, Jiangsu University, Zhenjiang 212013, China
}

*Corresponding Author: -

Email:xiefangwei@ujs.edu.cn

\begin{abstract}
: -
To enhance the fuel economy of automobile and extend the thermal fatigue duration of the typical shock absorbers, energy regenerative shock absorbers have enticed huge attention. Hydraulic electric energy-regenerative shock absorber (HERSA) is a new kind of shock absorber which can regenerate an amount of energy, dissipated as the heat energy in traditional shock absorber. This paper briefly describes HERSA's working principle, uses AMESim (hydraulic simulation software) to get damping attribute of HERSA as properly as conventional shock absorber through some theoretical and simulation tests. On the basis of simulation outcomes, we differentiate the hydraulic electric energy regenerative shock absorber (HERSA) and traditional shock absorber, and the results revealed that the inclusive performance of the prior is higher to that of the recent, but it shows the theoretical possibilities of HERSA's structure to improve fuel economy and ride comfort.
\end{abstract}

Keywords: - Shock absorber, AMESim simulation, Energy Regeneration, HERSA, damping force

\section{(c) $(\$)$}




\section{INTRODUCTION}

When driving on the road, many factors such as the bumping, speed and the steering may cause a relative vibration between sprung mass and un sprung mass. The damper turns the mechanical energy into heat through friction and dissipates it, so as to reduce the vibration of the vehicle. If this part of energy can be recycled, then it would be possible to reduce the fuel consumption and to achieve the purpose of energy saving. Since 1990s, many researchers have begun to study on the energy-regenerative suspension. The initial programs of energy retrieval were proposed by Suda and Shiiba [1] and Okada and Harada [2]. The programs of their theories were connected through linear DC generator. Though, the linear motor was normally very costly, and the effectiveness of the linear motor was much lesser than that of the rotary one. Graves et al. [3] research was related with electromagnetic regenerative damper. They concluded that energy recovery from this mechanism is small and may be relevant only for electric vehicles. They also suggest ways to increase the regenerative energy by enlarging the motion of shock; but, by doing this we cannot get the good dynamic result of vehicle. Goldner et al. [4] made electromagnetic (EM) shock absorbers to convert the energy dissipated in shock absorbers into electrical power. Zheng and $\mathrm{Yu}[5,6]$ suggested a study of novel energy-recovery active suspension. The study emphases on the performance enhancement in ride comfort and the energy recovery from road vibration. Kawamoto [7] on the energy absorbing damper Showed in- depth study, the theoretical study of the damping performance and balance of energy regeneration, improved the active energy-absorbing damper control. Gupta et al. [8] revealed that the rotary EM shock absorber can recover more energy than the linear EM shock absorber by conducting vehicle experimentations. Levant Power [9] corporation has built and verified two generation of 'GenShock' models for energy recovery and adaptive damping control. Li et al. [10] tested energy-recovery shock absorber based on rack and pinion mechanism, their program was proved to be realistic by both simulation and test results. But the damping and energy-regenerative properties of their program still needed to be enhanced. Dampers transform the up-and-down vibratory motion into a bidirectional rotation of the generator, which makes low mechanical reliability and energy regeneration efficiency. To eliminate such drawbacks, mechanical motion rectifiers[11, 12] were suggested. Zuo et al.[11] recognized the unidirectional generator rotation by applying two pairs of bevel gears and two oneway clutches on a rack-pinion-based EM shock absorber, and confirmed that the mechanical efficiency is highly improved. Wang et al. [12] recognized the similar effect by applying two overflow clutches and a planetary gearbox on a ball-screw-based EM shock absorber. So, A new type of shock absorber was discussed in this paper that not only provides high efficiency and smooth work, but also provides the easy way to understand active and semi-active control [13]

\section{Hydraulic electric energy regenerative shock absorber (HERSA) Working Principle}

Working phenomena of HERSA can be seen in fig. 1. The main parts of HERSA are a hydraulic cylinder, accumulators, hydraulic rectifier, hydraulic motor, generator, and pipelines. HERSA is another sort of shock absorber, which can produce an amount of hydraulic energy with the heat of vibration. Hydraulic cylinder's piston moves linearly from an external source of the signal and the oil passes through check valves. When the piston is moving up (compression stroke) the oil in the hydraulic cylinder region P2 passes through a hydraulic rectifier (check valve 2), Accumulator 2 (for smoothing) and finally through the hydraulic motor to rotate it by giving it energy. After Rotating Hydraulic motor the oil passes through Accumulator1, Hydraulic rectifier (Check valve 3) and comes back in hydraulic cylinder region P1. When a piston is moving down (extension stroke) the oil in region P1 moves towards the hydraulic rectifier (check valve 4), Accumulator 2 and come to Hydraulic motor. Hydraulic motor coupled with generator that produces electricity that can be utilized for battery charging purpose. By this way, the Hydraulic motor moves only in one direction. The main purpose of the Hydraulic rectifier is to make the unidirectional rotation of the motor. By this mechanism HERSA is doing an extra function of electricity generation.

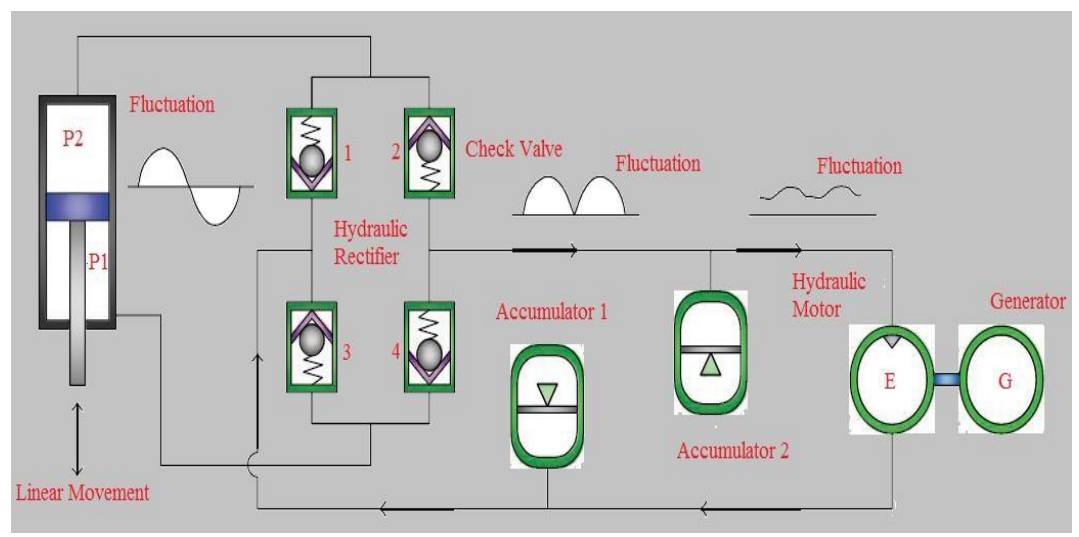

Figure1: Schematic Diagram of HERSA 


\section{Theoretical Analysis of Damping Characteristics of Model \\ 2.1 Ordinary shock absorber}

Ordinary shock absorber either single-cylinder or double-cylinder, its free body diagram (FBD) is shown in fig. 2 . F1 is the pressure force of the compression chamber oil acting on the bottom of the piston, F2 is the pressure force on the piston ring surface of the piston rod on the side of the piston rod, ; F3 for piston rod oil seal friction on the piston rod, and its direction is always the opposite to the direction of relative motion; ; F4 for the piston and the mechanical friction on the cylinder, and its direction is always the opposite to the direction of relative motion, F5 is the mechanical compression force acting on the piston rod by the external connection; F6 The pressure of the oil system expressed in gauge pressure, so, the Damper damping force can be calculated by given formula

$$
\Sigma \mathrm{F}=\mathrm{F} 2+\mathrm{F} 3+\mathrm{F} 4+\mathrm{F} 5+\mathrm{F} 6-\mathrm{F} 1
$$

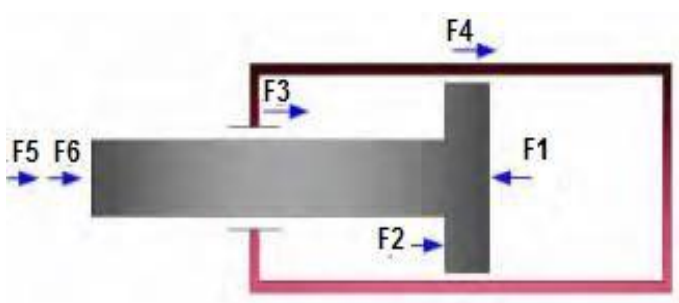

Figure2: Free body diagram of traditional shock

\subsection{Hydraulic Energy Regenerative Shock Absorber (HERSA).}

The Value of damping force of HERSA precisely depends on HERSA structure, parameters and state of motion. Mechanical properties of this system can be investigated by the value of damping force (F). It is also important to study the division of hydraulic (oil) energy in the system. For the investigation of Energy flow in the system, we used law of conservation of Energy at time $\Delta t$ and $(\Delta t \cong 0)$

$$
\mathrm{E}=\mathrm{E} 1+\mathrm{E} 2+\mathrm{E} 3+\mathrm{E} 4
$$

In the equation (2) $\mathrm{E}$ is the total hydraulic (oil) energy produced in the Hydraulic cylinder of HERSA, E1 is the loss of hydraulic pressure in the pipe due to friction. E2 is the energy loss of hydraulic oil while passing from check valve. E3 is the gain or release of energy by accumulator. E4 is the energy utilized by hydraulic motor to rotate it. Let the steel tube connected pipe used in the system and suppose the hydraulic oil used in the system is ideal fluid. By ignoring local losses and losses due to friction we can make $\mathrm{E} 1=0$. Only need to reset valve core of the spring used in one way valve, so the pressure required to open the valve is usually small about 0.03 to $0.05 \mathrm{MPa}$. The loss of pressure is very small e.g. less than $0.1 \sim 0.3 \mathrm{MPa}$ when valves opened, that is very small as compared to the pressure of system. As pressure loss is very small, we can ignore E2. Equation (2) implies as

$$
\mathrm{E}=\mathrm{E} 3+\mathrm{E} 4
$$

Above explained theoretical analysis, damping force $(\mathrm{F})$ of the device HERSA can be analyzed. So ignoring pipe pressure losses due to friction and pressure losses to open the check valve, the damping force $\mathrm{F}$ can be calculated as

$$
F=\left(P_{k}+P_{l}+P m\right) A_{k}
$$

Where $\mathrm{P}_{k}$ is the pressure in the cylinder which is recovering energy; $\mathrm{P}_{1}$ is the counter-pressure of the accumulator; $\mathrm{Pm}$ is the counter-pressure of the motor when it's driven and $A_{k}$ is the sectional area of the piston.

Suppose the diameter of hydraulic cylinder piston is D and the diameter of Piston rod is $\mathrm{D}_{\mathrm{r}}$ of HERSA device than

$$
\begin{aligned}
& A=\frac{\pi}{4} D^{2} \\
& A_{r}=\frac{\pi}{4} D_{r}^{2}
\end{aligned}
$$

Where $\mathrm{A}$ is area of cylinder piston and $\mathrm{A}_{\mathrm{r}}$ is the area of Piston rod.

\section{Simulation of System by AMESim}

AMESim is used for simulation performance of engineering system especially for Hydraulic system. It is made on an inbuilt graphical interface in which the system is exhibited throughout the simulation process. By the theory analyzed in last part, Hydraulic energy produced in Hydraulic cylinder is mainly distributed in Hydraulic motor and accumulator. Using this fact, we can construct the AMESim simulation model of HERSA. The model chiefly composed of three components: mechanical elements, energy storage elements and hydraulic elements. Mechanical part is the collection of hydraulic cylinder and hydraulic chamber; Hydraulic part is collection of one-way check valve, hydraulic motor, accumulator and pipeline. Energy storage part is collection of generator, storage battery and few lines. So, simulation model of HERSA is established as shown in Fig.3. To distinguish some important features between HERSA and Traditional shock absorber, the simulation model of traditional shock absorber is also set up, as shown in Fig. 4. So we generate some simulations of important feature of both system to analyze the properties of HERSA. 


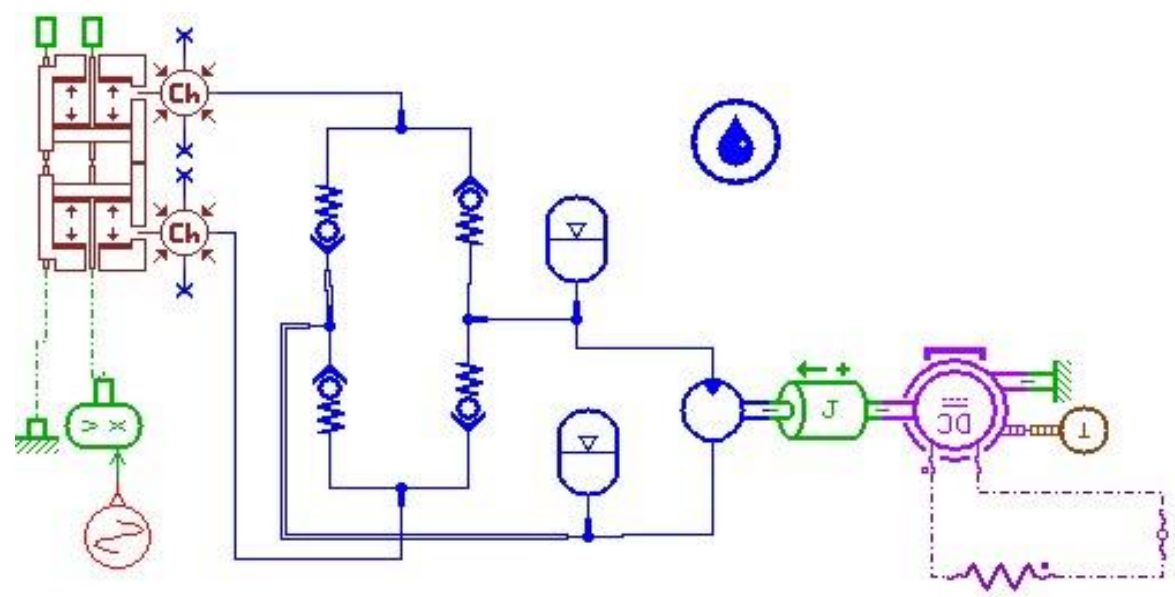

Figure3: Simulation Model of HERSA

By doing the simulation test on the model of hydraulic energy regenerative shock absorber (HERSA) and on the model of an ordinary shock absorber respectively, and setting the related parameters according to QC/T 545-1999 (automobile shock absorber bench test method). The simulation process is taken on the frequency of $1.67 \mathrm{~Hz}$ and $65 \mathrm{~mm}$ amplitude. The cylinder diameter is $45 \mathrm{~mm}$ while the piston rod diameter is $15 \mathrm{~mm}$. The simulation result of damping force is shown in figure $(5,6)$ for HERSA and traditional shock absorber respectively .
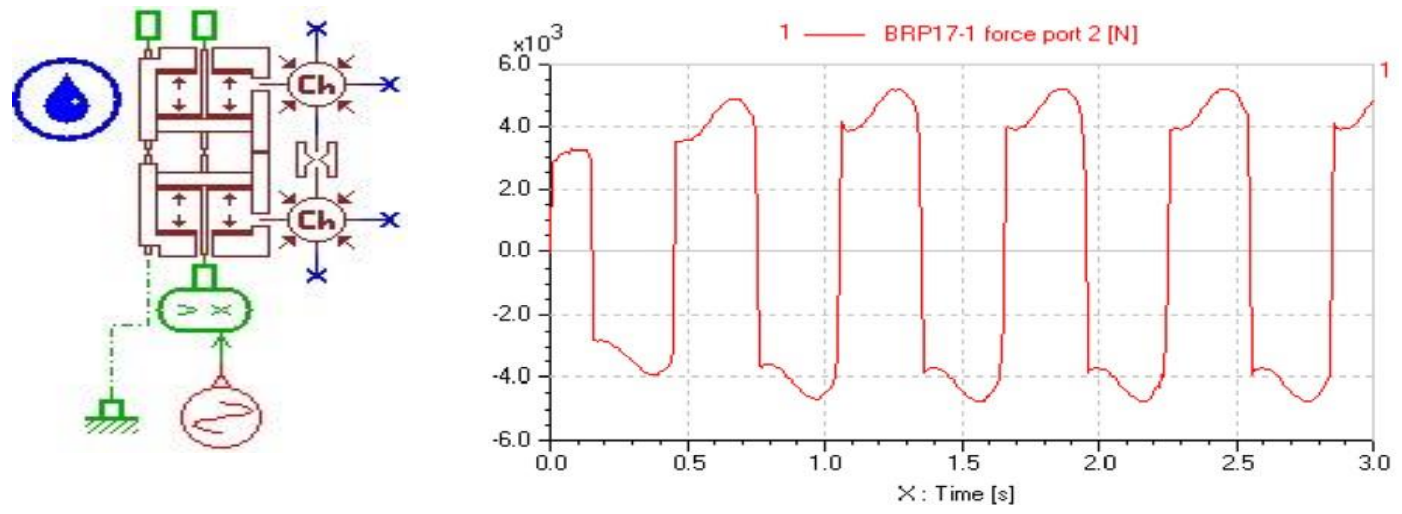

Figure4: Simulation model of traditional shock absorber

Figure5: Damping force on piston in HERSA

By the analysis of figure $5 \& 6$, the maximum damping force of ordinary damper is nearly $4 \mathrm{KN}$ that persists in a second, and it present for the time as the maximum speed of the piston. However, the maximum damping force of hydraulic energy-regenerative absorber has persisted during most time of the vibration period. but the damping force increases or decreases sharply when the piston is in maximum displacement. This change happened only in 0.01 second and it is due to the check valve opening and closing. Fig.7 reflect that properties of damping force gradually increased or decreased by the speed of piston in a traditional shock absorber, while fig. 8 tells that HERSA can show high damping force while the speed of piston is not so high. This fact is due to accumulator because it makes the hydraulic flow smooth, so that it passes in a stable state from the motor. Due to this stability fact damping force transmitted to the piston, act like a stable. So, more research is required. From fig. 9, Hydraulic energy regenerative shock absorber not only provides damping force but at the same time it also produce power of average around 1450W. So this is the major benefits of HERSA to regenerate power if we improved its drawbacks.

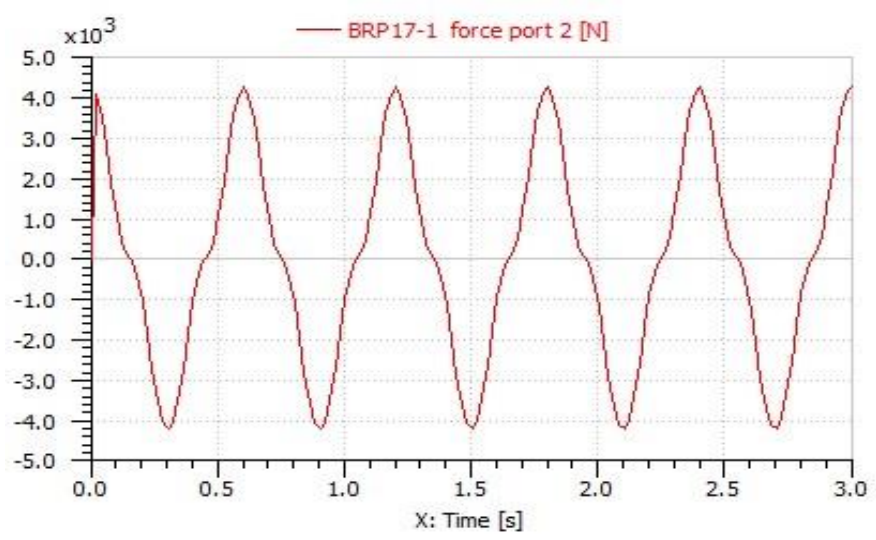

Figure6: Damping force on piston in traditional shock absorber 


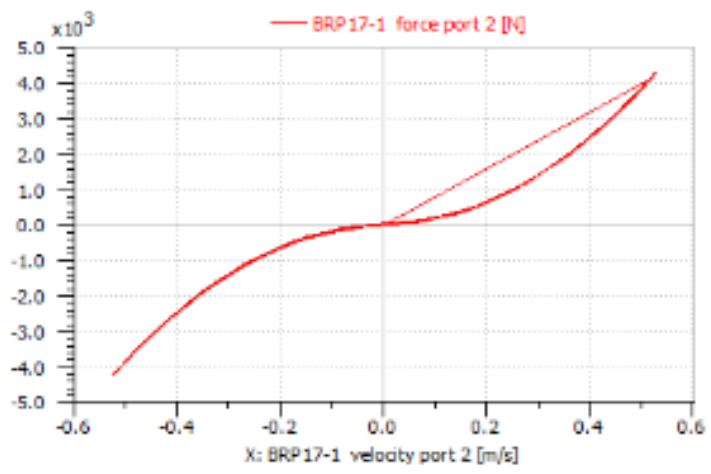

Figure7: Relationship between piston speed and damping force of ordinary shock absorber

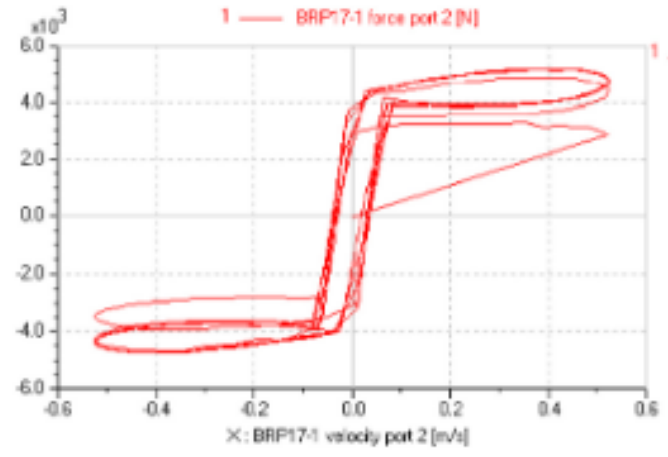

Figure8: Relationship between piston speed and damping force of HERSA

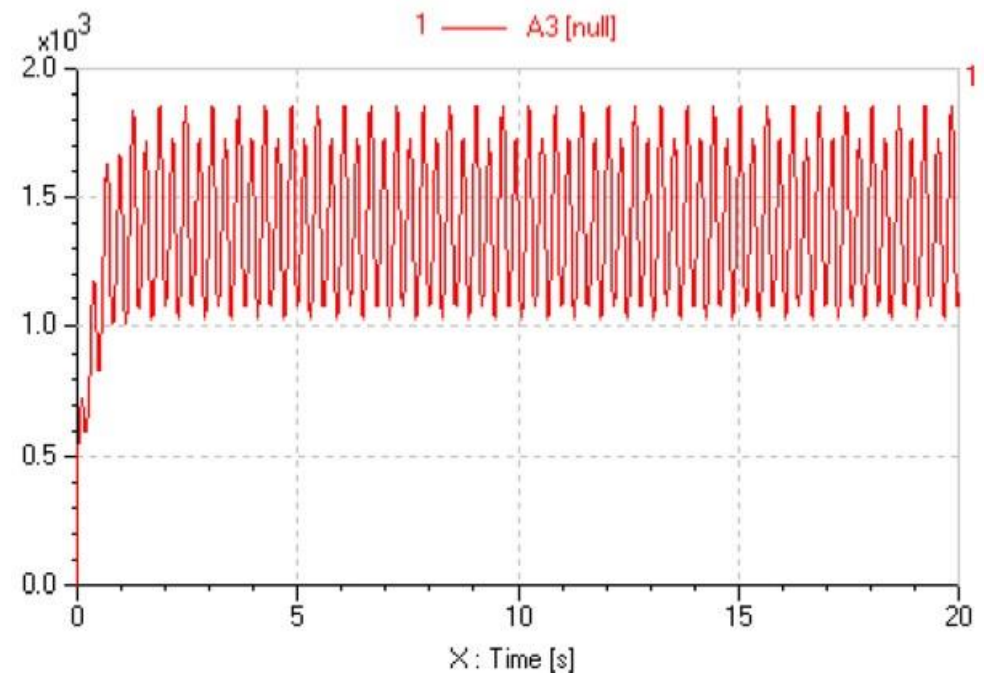

Figure9: power of Generator

\section{Conclusion}

A new kind of damper is discussed in this paper. We differentiate the damping force produced in traditional shock absorber and hydraulic electric energy regenerative shock absorber (HERSA) by the theoretical and simulation result, carried out by the software AMESim. Outcomes revelead that HERSA has its unique properties regarding its damping characteristics that can also be improved by its further study and by minimizing its drawback. Results also showed that HERSA can recover a handsome amount of power, which can be considered as one of its advantage .

\section{References}

[1].Suda, Y. and T. Shiiba, A new hybrid suspension system with active control and energy regeneration. Vehicle System Dynamics, 1996. 25(S1): p. 641-654.

[2].Okada, Y. and H. Harada. Regenerative control of active vibration damper and suspension systems. in Decision and Control, 1996., Proceedings of the 35th IEEE Conference on. 1996. IEEE.

[3].Graves, K.E., P.G. Iovenitti, and D. Toncich, Electromagnetic regenerative damping in vehicle suspension systems. International Journal of Vehicle Design, 2000. 24(2-3): p. 182-197.

[4].Goldner, R., P. Zerigian, and J. Hull, A preliminary study of energy recovery in vehicles by using regenerative magnetic shock absorbers. 2001, Tufts Univ., Dept of EECS (US).

[5].Zheng, X. and F. Yu, Study on the potential benefits of an energy-regenerative active suspension for vehicles. 2005, SAE Technical Paper.

[6].Zheng, X.-c., F. Yu, and Y.-c. Zhang, A novel energy-regenerative active suspension for vehicles. Journal of Shanghai Jiaotong University (Science), 2008. 13(2): p. 184-188.

[7].Kawamoto, Y., et al., Modeling of electromagnetic damper for automobile suspension. Journal of System Design and Dynamics, 2007. 1(3): p. 524-535.

[8].Gupta, A., et al., Design of electromagnetic shock absorbers. International Journal of Mechanics and Materials in Design, 2006. 3(3): p. 285-291.

[9].Mossberg, J., et al., Recovering energy from shock absorber motion on heavy duty commercial vehicles. 2012, SAE Technical Paper.

[10]. Li, Z., Z. Brindak, and L. Zuo. Modeling of an electromagnetic vibration energy harvester with motion magnification. in ASME 2011 International Mechanical Engineering Congress and Exposition. 2011. American Society of Mechanical Engineers. 
[11]. Li, Z., et al., Energy-harvesting shock absorber with a mechanical motion rectifier. Smart Materials and Structures, 2012. 22(2): p. 025008.

[12]. Wang, Q.-N., et al., Structure design and parameter matching of ball-screw regenerative damper. Journal of Jilin University(Engineering and Technology Edition), 2012. 42(5): p. 1100-1106.

[13]. Xu, L., Structure designs and evaluation of performance simulation of hydraulic transmission electromagnetic energy-regenerative active suspension. 2011, SAE technical paper. 